\title{
ADOPCIÓN DE LA ALIANZA PARA LA SEGURIDAD Y LA PROSPERIDAD DE AMÉRICA DEL NORTE (TLCAN-PLUS)
}

En la ciudad estadounidense de Waco, Texas, el 23 de marzo de 2005, los jefes de Estado de los Estados Unidos Mexicanos, Vicente Fox; Estados Unidos de América, George W. Bush, y el primer ministro de Canadá, Paul Martin, suscribieron la declaración conjunta de la Alianza para la Seguridad y la Prosperidad de América del Norte (ASPAN), también conocida como TLCAN-Plus.

La ASPAN que está denominada como "mecanismo de cooperación" y que se materializa en lo que también se le nombra como un Reporte a los Mandatarios, de junio de 2005, ${ }^{1}$ desde la perspectiva jurídica mexicana, es considerada como un "acuerdo interinstitucional", lo que significa que no pasa por el Senado, ni mucho menos le es aplicable la Ley de Tratados en Materia Económica, por lo que tampoco le es aplicable ningún control o contrapeso del legislativo. Lo cual es sumamente delicado, desde la perspectiva de un sistema que trata de crear controles y contrapesos y dada la importancia de las materias que toca la ASPAN así como su amplitud.

En efecto, el contenido de la ASPAN es muy amplio y de gran importancia para México, ya que se refiere a temas de gran trascendencia como Bienes de manufactura y Competitividad sectorial y regional, Movimiento de bienes; Comercio electrónico, Servicios financieros; Transporte; Energía; Medio ambiente, Agricultura y alimentos, Salud, y Seguridad.

Además se le dedica un par de capítulos a la seguridad de América del Norte contra amenazas tanto externa como interna, lo que manifiesta que si bien este acuerdo tiene por objeto la materia económica (de ahí su nombre de TLCAN-Plus) en la práctica pone su acento en la seguridad

1 Se puede consultar en: http://info.sct.gob.mx/fileadmin/ASPAN/Spanish___Annex2.pdf 
de América del Norte. Es tanto el acento en materia de seguridad, que algunos observadores opinan que es el objetivo fundamental de la ASPAN, dado que responde a las medidas de seguridad de los Estados Unidos, después del 11 de septiembre, en contra del terrorismo. De ahí que se pretenda cerrar las fronteras de Norte América.

Por otra parte, si bien la ASPAN contiene en algunos casos políticas y obligaciones concretas, en otros casos solamente son directrices, por eso esta considerado como "un proceso de cooperación continuo que establecerá mecanismos de consulta permanentes para recibir las opiniones y aportaciones de la sociedad mexicana; tanto de organizaciones de la sociedad civil, instituciones públicas y privadas especialistas en temas de política exterior, como de todos aquellos ciudadanos mexicanos interesados en enriquecer con sus trabajos los temas comprendidos en las agendas de la ASPAN". 2 Aunque en la práctica, por lo menos desde la perspectiva mexicanos esa idea de "aportaciones de la sociedad mexicana" no se haya dado.

En virtud de la importancia y trascendencia de la ASPAN, se insiste, es necesario someterlo a los controles estatales que no lo tiene un simple acuerdo interinstitucional.

Manuel BECERRA RAMÍREZ*

2 Véase Alianza para la Seguridad y Prosperidad de América del Norte, Reporte a los Mandatarios, junio de 2005, en http://www.sre.gob.mx/eventos/aspan/

* Investigador del Instituto de Investigaciones Jurídicas de la UNAM. 